\title{
REVIEW OF 3-YEAR OUTCOMES OF A VERY-LOW-ENERGY DIET-BASED OUTPATIENT OBESITY TREATMENT PROGRAMME
}

Priya Sumithran ${ }^{1,2}$, Luke A. Prendergast ${ }^{3}$, Cilla J. Haywood ${ }^{1,2}$, Christine A. Houlihan ${ }^{1}$ and Joseph Proietto ${ }^{1,2}$

${ }^{1}$ Weight Control Clinic, Austin Health, ${ }^{2}$ University of Melbourne, Department of Medicine (Austin Health), ${ }^{3}$ La Trobe University, Department of Mathematics and Statistics

\section{Keywords:}

Very-low-energy diet, VLED, outpatient, weight management clinic

\section{Running title:}

Review of weight management clinic 3 year outcomes

\section{All correspondence to:}

Professor Joseph Proietto

Weight Control Clinic, Austin Health

Heidelberg Repatriation Hospital

300 Waterdale Rd,

Heidelberg 3081

Victoria

Tel: +61394962250

Fax: +61 394974554

Email: j.proietto@unimelb.edu.au 
What is already known about this subject

- a multidisciplinary approach is recommended for the treatment of obesity

- weight loss achieved using lifestyle methods alone is usually regained over time

- attrition from long-term weight management programmes is high

What this study adds

- this review assessed long-term (3-year) outcomes of a dedicated outpatient obesity treatment clinic

- clinically beneficial weight loss can be achieved using a medically-supervised verylow-energy diet, continued follow-up and consideration of pharmacotherapy to prevent weight regain

- several baseline characteristics were identified as predictors of attrition 


\begin{abstract}
Background: Obesity is a complex disorder which requires a multidisciplinary treatment approach. This review evaluated 3-year outcomes of a very-low-energy diet (VLED)-based programme at a tertiary hospital multidisciplinary weight management clinic.
\end{abstract}

Methodology: Medical records of all patients who agreed to undertake the VLED programme and who did not undergo bariatric surgery during the 3-year follow-up period were examined. Baseline data collection included demographic and anthropometric characteristics, childhood onset of obesity, and co-existing medical conditions. Weight was modelled using a Linear Mixed Effects analysis. Logistic regression analyses were used to model the probability of continuing to attend the clinic and to identify pre-treatment factors associated with longer duration of attendance.

Results: Data from 1109 patients were included. 231 patients (19.2\%) were still attending the clinic 3 years after their initial appointment. Mean weight loss among patients who attended the clinic for 3 years was $6.4 \mathrm{~kg}(3.5 \%, 95 \%$ CI 2.8, 4.2\%). People who were prescribed pharmacotherapy maintained a greater weight loss at 3 years $(7.7 \%$ vs $2.3 \%$ without pharmacotherapy, 95\% CI for difference 3.9, 7.0\%). People who had an onset of obesity in childhood, who had co-existing hypertension or coronary artery disease, and who did not currently smoke were more likely to continue to attend the clinic for up to 3 years.

Summary: In an outpatient weight management clinic, patients who undertook a VLEDbased programme and continued in follow-up achieved a clinically significant weight loss at 3 years, particularly if pharmacotherapy was used for weight loss maintenance. 


\section{INTRODUCTION}

In Australia, almost two thirds (63\%) of adults are overweight or obese (1). Since obesity is a complex and multifactorial disorder, a multidisciplinary treatment approach is recommended, including dietary and exercise components, behaviour modification, and consideration of pharmacotherapy and bariatric surgery in selected patients (2). Weight loss achieved using lifestyle methods alone is usually regained over time $(2,3)$, therefore it is imperative that evidence-based weight-loss programmes including strategies to prevent weight regain are developed and assessed.

Our hospital, a tertiary referral centre in metropolitan Melbourne, established a Weight Control Clinic in February 2004. The clinic offers an appointment to all adult patients referred with a body mass index (BMI) above $35 \mathrm{~kg} / \mathrm{m}^{2}$, or $>30 \mathrm{~kg} / \mathrm{m}^{2}$ with a weight-related comorbidity, who have made a previous unsuccessful attempt to lose weight or maintain weight loss. The treatment programme is based on the following premises: the predisposition to obesity has a genetic and/or epigenetic basis $(4,5)$; body weight is physiologically defended (6-8); a very-low-energy diet (VLED) is more effective than a hypocaloric balanced diet for initial weight loss $(3,9)$; over the long-term, weight regain is likely $(2,3)$ therefore long-term follow-up is required, pharmacotherapy to suppress appetite should be offered to people who are unable to maintain weight loss, and bariatric surgery should be available for those who have failed medical therapy.

\section{Treatment programme}

The programme comprises an initial weight-loss phase using a VLED, and an indefinite longterm weight-loss maintenance phase. A medical evaluation of patients, including a 
comprehensive medical history and physical examination, is undertaken before initiating the VLED. During the period reviewed, patients were recommended either a full VLED regimen (3 meal replacement products plus 2 cups of non-starch vegetables daily; approximately 2300 $\mathrm{kJ}$ [550 kcal] per day) or a partial regimen (2 meal replacement products, plus one meal consisting of lean protein and 2 cups of non-starch vegetables; approximately $3350 \mathrm{~kJ}$ [800 kcal] per day), depending on clinical factors and patient preference. During the VLED phase, appointments are scheduled every 2-4 weeks for monitoring of weight, blood pressure, and medical conditions (e.g. adjustment of medications for diabetes if required).

Before entering the long-term weight maintenance phase, dietary and lifestyle modifications are discussed. Patients then make a transition from VLED to regular foods over several weeks, with introduction of a relatively high-protein reduced-carbohydrate diet. During the transition and weight maintenance phases, patients are reviewed every 1-3 months.

For patients unable to maintain weight loss despite lifestyle modification, pharmacotherapy may be used for appetite reduction. During the period under review, the medication most often prescribed was sibutramine 10-15mg daily. Other pharmacotherapy prescribed included topiramate $25-100 \mathrm{mg}$ bd, phentermine $15-40 \mathrm{mg}$ daily, exenatide $5-10 \mathrm{mcg}$ bd in people with type 2 diabetes, and following the withdrawal of sibutramine from the Australian market in 2010, the combination of phentermine $15 \mathrm{mg}$ and topiramate $12.5-50 \mathrm{mg}$ daily. Patients who regain weight despite lifestyle modification and pharmacotherapy, or in whom pharmacotherapy is contraindicated, are offered a referral for bariatric surgery. There are no fees for clinic appointments. Patients purchase the VLED products at their own expense, and the cost of pharmacotherapy is subsidised (cost to the patient $\$ 12$ to $\$ 50$ (AUD) per month depending on medication type, dose and patient's eligibility for concession). The aim of this 
report is to evaluate the 3 -year outcomes of this treatment programme. The Austin Health Human Research Ethics Committee approved this review.

\section{METHODS}

Medical records of all patients who attended the clinic between February 2004 and December 2012 were examined. Patients whose first appointment was between February 2004 and December 2009, who attended the clinic at least once, and agreed to undertake the VLED programme were included in this review of 3 year outcomes. All patients referred to the clinic were made an appointment, and if an appointment was missed, another was booked, of which patients were notified by letter, on at least two occasions, before patients were considered lost to follow-up.

\section{Data extraction}

Information extracted from the record of the initial visit included age, gender, height, weight, whether the onset of obesity occurred in childhood, triggers for weight gain, medical conditions, current medications, and management plan (to identify eligibility for this review). Follow-up data included body weight up to 3 years after the initial visit, date of last attendance at the clinic, and whether patients underwent bariatric surgery. Whether or not pharmacotherapy was prescribed was extracted for patients who attended clinic for at least 3 years. Information regarding changes in medical conditions and medications was not systematically collected.

\section{Statistical analysis}

Descriptive data are expressed as means \pm standard deviations. Baseline characteristics were compared between men and women, and between completers (people who attended for at 
least 3 years) and drop-outs using independent sample t-tests. Analyses of binary outcomes were carried out using logistic regression with a logit link function. Profile likelihood 95\% confidence intervals were computed for the odds ratios. Due to the large number of covariates, stepwise model selection based on the Akaike information criterion (AIC) was used. Prediction rates were calculated using ten-fold cross-validation. To account for the irregularity of time points at which patients attended the clinic, and the within-subject correlation of weight over time, weight was modeled using a Linear Mixed Effects (LME) analysis with time treated as a continuous covariate which included polynomial terms up to and including order four to allow for non-linear change. Additionally, an intention-to-treat (ITT) analysis was undertaken, in which patients who stopped attending the clinic before three years' follow-up were assumed to have returned to their baseline weight. Maximum percentage weight loss recorded during the three years was analysed using multiple linear regression to adjust for covariates. Stepwise model selection based on the AIC was used to select factors contributing most to the model.

\section{RESULTS}

\section{Clinic population}

Of the 2074 patients who attended their first appointment between February 2004 and December 2009, 1287 (62\%) agreed to commence the VLED programme. Of them, 178 underwent bariatric surgery during the follow-up period and were excluded from analyses. Baseline characteristics of the remaining 1109 patients are given in Table 1. Approximately one third of patients were male. Men were heavier than women $(137.9 \pm 33.4$ vs $119.0 \pm$ $26.0 \mathrm{~kg} ; \mathrm{p}<0.001)$, but body mass index $(\mathrm{BMI})$ was not different between genders $(44.9 \pm 9.9$ vs $45.4 \pm 9.0 \mathrm{~kg} / \mathrm{m}^{2} ; \mathrm{p}=0.39$ ). More than half of patients had hypertension, nearly half had obstructive sleep apnoea and one third had type 2 diabetes. 


\section{Attrition}

Attrition from the clinic over time is depicted in Figure 1. The median duration of attendance was 248 days. Nine hundred and twenty-two patients $(83.1 \%)$ returned for at least one follow-up visit, and $466(42.0 \%)$ and $213(19.2 \%)$ were still attending 1 and 3 years after their initial appointment. A logistic regression analysis of pre-treatment factors associated with longer duration of attendance, repeated at one and three years to model the probability of patients continuing to attend the clinic at these times, is given in Table 2. Several baseline variables were consistent predictors of attendance: people who were obese as children, who had hypertension or coronary artery disease, and who did not smoke were more likely to continue to attend for up to 3 years. Gender, age, blood pressure at the initial appointment and mental illness did not affect attrition. The models estimated the probability of continued attendance at 1 and 3 years with 76 and $83 \%$ accuracy, respectively (Table 2).

\section{Weight loss}

In plot A of Figure 2, weight changes recorded at clinic appointments for up to 3 years for each of the 1109 patients who agreed to start the VLED programme are depicted. For clarity, mean weight changes estimated using the LME analysis at specified time points are provided in Plot B of Figure 2. Table 3 shows estimated means and associated 95\% confidence intervals at one, two and three years for all continuing patients, and an ITT analysis assuming return to baseline weights for patients who stopped attending. The mean weight loss among patients continuing to attend the clinic was $9.7 \mathrm{~kg}(6.2 \%)$ at 1 year, and $6.4 \mathrm{~kg}(3.5 \%)$ at 3 years. The mean maximum weight loss percentage, and contributing factors identified in the analysis, are given in Table 4, for the 1109 patients who agreed to commence the VLED (including people who did not attend any further appointments and were assumed to have 
remained at their initial weight), and the 922 people who attended at least one follow-up visit. People who returned for at least one follow-up appointment achieved a mean maximum weight loss of $9.2 \%$ [95\% CI 8.6, 9.7]. Factors associated with greater maximum weight loss were higher baseline BMI, systolic blood pressure and age, but effect sizes were small (for example, for every $1 \mathrm{~kg} / \mathrm{m}^{2}$ increment in initial BMI, maximum weight loss was estimated to increase by $0.09 \%$ ). Conversely, smoking and a history of mental illness were associated with lower maximum weight loss. Gender, having English as a first language, childhood onset of obesity, and a history of hypertension, coronary disease, asthma and diabetes were not associated with maximum weight loss percentage.

Of the 213 patients who attended the clinic for at least 3 years, more than half (53\%) had a final recorded weight at least $5 \%$ below their initial weight, and $33 \%$ were maintaining a weight loss of $10 \%$ or more. Fifty $(23 \%)$ of them had been prescribed pharmacotherapy for appetite reduction during the follow-up period. At their closest appointment date to 3 years, mean weight loss was significantly greater among people who were prescribed pharmacotherapy than those who were not (mean weight loss 7.7 vs $2.3 \%, 95 \%$ CI for difference $-3.9,-7.0 \%)$.

\section{DISCUSSION}

This retrospective review assessed 3-year outcomes after establishment of an obesity treatment clinic in a large metropolitan hospital, using an evidence-based treatment programme comprising an initial VLED, structured reintroduction of regular foods, and continued follow-up with consideration of pharmacotherapy to prevent weight regain. Patients who attended at least one follow-up appointment achieved a mean maximum weight loss of $9.2 \%$, and those who continued to attend for 3 years maintained a mean loss of $6.4 \mathrm{~kg}$ $(3.5 \%)$. 
It is difficult to directly compare the weight outcomes from our clinic with others due to the heterogeneity of the patient populations and treatment methods among reports. Furthermore, there are few reports of outcomes beyond 1 year. In general, our patients have more severe obesity and a greater prevalence of co-existing medical conditions, and the frequency of appointments at our clinic is less compared with many others reported. A programme using a liquid low-energy diet for 12-weeks (or 20kg weight loss) followed by structured reintroduction of food and optional pharmacotherapy (orlistat) for 12 months in a primary care setting in 91 people with severe obesity (mean age 46 years, BMI $48.0 \mathrm{~kg} / \mathrm{m}^{2}$ ) achieved a weight loss of $10.8 \%$ at 12 months in the $57 \%$ of patients who completed the programme (10). Rolland and colleagues reported outcomes of another UK community-based programme (11), in which 5965 participants (mean BMI $36.3 \mathrm{~kg} / \mathrm{m}^{2}$ ) undertook a VLED for an average of 20 weeks, followed by a weight maintenance phase including weekly transactional cognitive behavioural therapy. In their analysis of completers, weight loss was $17.6 \%$ at 1 year, and $12.9 \%$ at 3 years. The weight losses achieved in these programmes are superior to our clinic results, which may partly be explained by the exclusion from the community programmes of people with co-morbidities which may confer greater difficulty in losing weight (such as psychiatric illnesses, and use of insulin or sulfonylureas for diabetes), and the more intensive schedule of follow-up visits compared to our clinic. Among outpatient-based reports, a retrospective analysis of a programme in 1887 patients (mean BMI $38.2 \mathrm{~kg} / \mathrm{m}^{2}$ ) using 12 weeks of liquid meal replacements (520 or $850 \mathrm{kcal} / \mathrm{d}$ ) without pharmacotherapy, but with an intensive follow-up period of weekly clinic visits, reported a mean initial weight loss of approximately $15 \%$ at 12 weeks, and $10 \%$ at 48 weeks in patients who continued to attend the clinic (12). A prospective multicentre German study in 8296 participants (mean BMI 40.8\%) which comprised a 12-week meal replacement diet 
(800 kcal/d) followed by structured refeeding, weight stabilisation and weight maintenance phases, and also included weekly clinic visits, reported an impressive 1 year weight loss of $17.9 \%$ (13). However, in the subgroup of 301 participants with longer-term follow-up, mean weight loss at 3 years was $5.9 \mathrm{~kg}(4.2 \%)$. In a retrospective review of 51 older outpatients with a high prevalence of obesity-related comorbidities (mean age 65.2 years, BMI 38.5 $\mathrm{kg} / \mathrm{m}^{2}$ ) prescribed a hypocaloric diet and a variety of pharmacotherapy who continued followup for at least 6 months (mean duration 39 months), initial weight loss was $5.7 \mathrm{~kg}$ (approximately 6\%) at 6 months, and at their last recorded evaluation, mean weight loss was $6.65 \mathrm{~kg}, 67 \%$ of patients were maintaining a loss of $5 \%$, and $33 \%$ a loss of $10 \%$ of their initial weight (14). A similar result was reported in a long-term telephone follow-up of a 26-week program comprising an initial 12-week VLED, structured refeeding and maintenance and weekly clinic appointments, in which loss of $\geq 5 \%$ weight was maintained by $53 \%$ and $\geq 10 \%$ of weight by $35 \%$ of participants (15). These long-term results are very similar to the weight loss achieved by patients still attending our clinic at 3 years, and indicate that although some weight regain is common after 6-12 months, clinically relevant weight loss in the longer term is possible with a medical treatment programme, if strategies are used to assist with maintenance of weight loss.

Attrition from long-term obesity management programmes is notoriously high, and is expected to be higher from real-world outpatient clinics compared with research studies, in which methods to reduce drop-out are often employed, such as run-in periods in which nonadherent patients are screened out, and offering patients financial and other incentives to encourage retention. Our rate of attrition at 12 months is in keeping with that reported in other non-surgical weight loss clinics $(16,17)$. Gill and colleagues retrospectively reviewed attrition from a multidisciplinary clinic in Canada, including 887 participants in a medical 
weight loss programme and 318 surgically-treated patients (16). Comparable to ours, this was a publicly funded urban clinic, with a predominance of female patients, mean age of 43 years, initial BMI $50.6 \mathrm{~kg} / \mathrm{m}^{2}$, and a considerable proportion of patients (46\%) with a mental illness. However, in contrast to our clinic, a rigorous lead-in period must be completed in order to receive an appointment, and if an appointment is missed, an intensive effort to contact the patient is made over 12 months before they are considered lost to follow-up (16). Attrition at 12 months was $53.9 \%$ in the medical clinic and $11.9 \%$ from the surgical clinic. Participation in the medical (vs surgical) clinic, lower BMI, lack of co-existing musculoskeletal disease, and presence of a mental illness were identified as predictors of attrition (16). A retrospective review of predictors of attendance at an outpatient obesity clinic in an Australian tertiary hospital with similar patient characteristics to ours found that almost half of patients referred did not complete the questionnaire required to book their first appointment, and a further $17 \%$ did not attend their first appointment (18). Fifty-five percent of patients attending the clinic lost weight. Patients with diabetes were more likely to return their questionnaire, and those with hypercholesterolemia were more likely to lose weight (18). In a meta-analysis of predictors of attrition from 24 randomised controlled trials of weight-loss medications, Fabricatore and colleagues (19) found that attrition at 1 year was greater in participants who received placebo compared with those treated with either orlistat or sibutramine (34.9 vs 28.6 and $28.3 \%$ respectively), and in groups which did not undergo a pre-randomisation lead-in period than in those that did $(39.9$ vs $29.1 \%, \mathrm{p}<0.01)$. In univariable analyses, the presence of a weight-related comorbidity was related to lower total and non-adverse event-related attrition, but this did not remain a significant factor in the final multivariable model. In keeping with our findings, age was not related, and there was limited evidence for BMI as a predictor of attrition (19). Inelmen and colleagues reported that patients who completed a 12 month lifestyle intervention had a greater number of obesity- 
related diseases than those who dropped out (17). Therefore, we and others (16-19) have found that the presence of various physical conditions related to excess weight are predictive of continued attendance. Possible explanations for this are a greater perceived urgency for weight loss, stronger support from family members and healthcare providers, and greater concern about the health implications of obesity, which may increase tolerance of treatmentrelated adverse effects and inconveniences (19).

Retrospective chart reviews have inherent limitations. Patients were considered to have coexisting medical conditions (hypertension, dyslipidaemia, type 2 diabetes, mental illness) if they were taking medications for them or if the condition was noted in the medical history. Information regarding current symptoms, changes in medications or biochemical parameters was not systematically collected. Although we found that mental illness was not associated with attrition, we did not have information to distinguish between different types of illness, or the presence of active symptoms. Others have reported mixed findings regarding the association between symptoms of depression and attrition $(17,20)$. It was also not possible to determine the reasons for drop-out from the clinic. The fixed timing of the clinic (on a weekday morning) is likely to be a barrier for people who have conflicting commitments which are not flexible (17). Furthermore, the high rate of refusal to commence the VLED programme (38\%) and early discontinuation (17\% who agreed to it but failed to return after their initial appointment) suggests a discrepancy between patients' expectations and the programme offered. In order to address this, newly referred patients are now being sent information about the programme and invited to make an appointment if they wish to proceed. 
Among our patients, mean weight loss at 3 years was significantly greater in those who had been prescribed pharmacotherapy. Weight loss achieved without bariatric surgery is accompanied by adaptive changes in energy expenditure and several hormones involved in appetite regulation, which collectively facilitate weight regain (21). During the period under review, most patients were prescribed either sibutramine, or combination phentermine and topiramate for appetite reduction. In Australia, the only medication currently approved for long-term obesity treatment is orlistat, which is superior to placebo in reducing weight regain in clinical studies, but which does not attenuate the increased appetite which follows dietinduced weight loss (22). Since 2012, four new or combination medications which reduce appetite have been approved by the U.S. Food and Drug Administration for the long-term management of obesity - controlled-release phentermine-topiramate, lorcaserin, naltrexonebupropion, and liraglutide (23). When available, pharmacotherapy with proven long-term safety and efficacy would be a useful adjunct to lifestyle modification for people who are otherwise unable to maintain weight loss.

\section{CONFLICTS OF INTEREST STATEMENT}

$\mathrm{JP}$ is chairman of the medical advisory board for liraglutide $3 \mathrm{mg}$, and has received payment for consultancy from Astra Zeneca and Eli Lilly, and lectures from iNova pharmaceuticals unrelated to this paper. PS has received payment for lectures from Nestlé and Novo Nordisk unrelated to this paper. The other authors have no conflicts of interest relevant to this paper.

\section{ACKNOWLEDGEMENTS}

We thank Abang M.N.A. Samatan for his work on an early version of this review, and Rodney Camba and Nick Jandric for IT assistance. Author contributions are as follows: PS, 
CJH, CAH and JP collected the data, LAP and PS analysed the data, PS, LAP, and JP wrote the manuscript. 


\section{REFERENCES}

1. Australian Bureau of Statistics, 2012. Australian Health Survey: First Results, 2011-12, cat. no. 4364.0.55.001, viewed 8 Sept 2015,

\section{http://www.abs.gov.au/ausstats/abs@.nsf/Lookup/4364.0.55.001Chapter1002011-12}

2. National Health and Medical Research Council 2013. Clinical Practice Guidelines for the management of overweight and obesity in adults, adolescents and children in Australia. Melbourne: National Health and Medical Research Council.

3. Anderson JW, Konz EC, Frederich RC, Wood CL. Long-term weight-loss maintenance: a meta-analysis of US studies. Am J Clin Nutr 2001;74:579-84

4. Stunkard AJ, Foch TT, Hrubec Z, A twin study of human obesity. JAMA 1986; 256:51-4.

5. Gluckman PD and Hanson MA. Developmental and epigenetic pathways to obesity: an evolutionary-developmental perspective. Int J Obes (Lond) 2008; 32 Suppl 7:S62-71.

6. Woods SC, D'Alessio DA. Central control of body weight and appetite. J Clin Endocrinol Metab 2008; 93(Suppl 1):S37-50.

7. Sumithran P, Prendergast LA, Delbridge E et al. Long-term persistence of hormonal adaptations to weight loss. N Engl J Med 2011;365:1597-604.

8. Rosenbaum M, Hirsch J, Gallagher DA, Leibel RL. Long-term persistence of adaptive thermogenesis in subjects who have maintained a reduced body weight. Am J Clin Nutr 2008, 88:906-12

9. Purcell K, Sumithran P, Prendergast LA, Bouniu CJ, Delbridge E, Proietto J. The effect of rate of weight loss on long-term weight management: a randomised controlled trial. Lancet Diabetes Endocrinol 2014, 2:954-62.

10. Lean ME, Brosnahan N, McLoone P et al. Feasibility and indicative results from a 12month low-energy liquid diet treatment and maintenance programme for severe obesity. $\mathrm{Br} J$ Gen Pract 2013, 63:e115-24. 
11. Rolland C, Johnston KL, Lula S, Macdonald I, Broom J. Long-term weight loss maintenance and management following a VLCD: a 3-year outcome. Int J Clin Pract 2014; $68: 379-87$.

12. Bailey BW, Jacobsen DJ, Donnelly JE. Weight loss and maintenance outcomes using moderate and severe caloric restriction in an outpatient setting. Dis Manag 2008, 11:176-80. 13. Bischoff SC, Damms-Machado A, Betz C et al. Multicenter evaluation of an interdisciplinary 52-week weight loss program for obesity with regard to body weight, comorbidities and quality of life - a prospective study. Int J Obes 2012;36:614-24.

14. Horie NC, Cercato C, Mancini MC, Halpern A. Long-term pharmacotherapy for obesity in elderly patients: a retrospective evaluation of medical records from a specialized obesity outpatient clinic. Drugs Aging 2010, 27:497-506.

15. Wadden TA and Frey DL. A multicenter evaluation of a proprietary weight loss program for the treatment of marked obesity: a five-year follow-up. Int J Eat Disord 1997;22:203-12. 16. Gill RS, Karmali S, Hadi G, Al-Adra DP, Shi X, Birch DW. Predictors of attrition in a multidisciplinary adult weight management clinic. Can J Surg 2012, 55:239-43.

17. Inelmen EM, Toffanello ED, Enzi G et al. Predictors of drop-out in overweight and obese outpatients. Int J Obes 2005, 29:122-8.

18. Brook E, Cohen L, Hakendorf P, Wittert G, Thompson C. Predictors of attendance at an obesity clinic and subsequent weight change. BMC Health Serv Res 2014; 14:78

19. Fabricatore AN, Wadden TA, Moore RH, Butryn ML, Heymsfield SB, Nguyen AM. Predictors of attrition and weight loss success: results from a randomized controlled trial. Behav Res Ther 2009;47:685-91.

20. Mazzeschi C, Pazzagli C, Buratta L et al. Mutual interactions between depression/quality of life and adherence to a multidisciplinary lifestyle intervention in obesity. J Clin Endocrinol Metab 2012;97:E2261-5. 
21. Sumithran P, Proietto J. The defence of body weight: a physiological basis for weight regain after weight loss. Clin Sci 2013;124:231-41.

22. Sumithran P, Proietto J. Benefit-risk assessment of orlistat in the treatment of obesity. Drug Saf 2014;37:597-608.

23. Apovian CM, Aronne LJ, Bessesen DH et al. Pharmacological management of obesity: an Endocrine Society clinical practice guideline. J Clin Endocrinol Metab 2015;100:342-62. 


\section{TABLES}

\begin{tabular}{|c|c|}
\hline \multicolumn{2}{|l|}{ Descriptives [means \pm SD] } \\
\hline Men/Women (n, \%) & $350(31.6 \%) / 759(68.4 \%)$ \\
\hline Age (years) & $48.3 \pm 13.1$ \\
\hline Weight (kg) & $125.0 \pm 29.8$ \\
\hline BMI $\left(\mathrm{kg} / \mathrm{m}^{2}\right)$ & $45.3 \pm 9.3$ \\
\hline SBP (mmHg) & $134.1 \pm 18.4$ \\
\hline DBP $(\mathrm{mmHg})$ & $80.5 \pm 13.6$ \\
\hline Waist circumference $(\mathrm{cm})$ & $127.8 \pm 17.9$ \\
\hline Hip circumference $(\mathrm{cm})$ & $137.6 \pm 18.6$ \\
\hline \multicolumn{2}{|l|}{ Comorbidities $[\mathrm{n}(\%)]$} \\
\hline Smoker & $191(18.5 \%)$ \\
\hline Hypertension & $585(56.7 \%)$ \\
\hline Dyslipidemia & $360(35.0 \%)$ \\
\hline OSA & $482(46.8 \%)$ \\
\hline T2DM & $347(33.7 \%)$ \\
\hline Coronary artery disease & $96(9.3 \%)$ \\
\hline Obese in childhood & $374(36.3 \%)$ \\
\hline Mental illness* & $336(32.6 \%)$ \\
\hline
\end{tabular}

Table 1. Baseline characteristics. For descriptives, $n=1109$. For comorbidities, $n=1029-1032$. * includes depression, anxiety, bipolar disorder, schizophrenia. 


\begin{tabular}{|l|c|c|}
\hline & 1 year & 3 years \\
\hline Still attending (n; \%) & $466 ; 42.0 \%$ & $213 ; 19.2 \%$ \\
\hline Prediction rate (\%) & 75.9 & $1.42(1.00,2.01)^{*}$ \\
\hline Obese child & $1.38(1.03,1.85)^{*}$ & $1.42(0.99,2.05)$ \\
\hline Type 2 diabetes & $1.02(1.00,1.03)^{*}$ & \\
\hline Body mass index & $1.01(1.00,1.02)$ & $1.45(1.02,2.07)^{*}$ \\
\hline Diastolic blood pressure & & $0.53(0.31,0.87)^{*}$ \\
\hline Asthma & $0.72(0.49,1.03)$ & $1.66(1.13,2.45) \dagger$ \\
\hline Smoker & $0.53(0.28,0.99)^{*}$ & $1.67(1.00,2.77)^{*}$ \\
\hline English as first language & $1.69(1.26,2.26) \ddagger$ & \\
\hline Hypertension & $1.82(1.13,2.98)^{*}$ & \\
\hline Coronary artery disease & & \\
\hline
\end{tabular}

Table 2 Estimated odds-ratios [OR $(95 \% \mathrm{CI})]$ for factors contributing to probability of still attending the clinic at 1 and 3 years after the initial appointment. $* \mathrm{p} \leq 0.05, \dagger p \leq 0.01, \$ p<0.001$. Prediction rate (\%) refers to the strength of the model with respect to predicting whether or not a patient is still attending at the nominated timepoint. 


\begin{tabular}{|l|c|c|c|c|}
\hline & \multicolumn{2}{|c|}{ Still attending } & \multicolumn{2}{c|}{ Intention-to-treat } \\
\hline & Weight change kg & Weight change \% & Weight change kg & Weight change \% \\
\hline 1 year & $-9.7(-10.3,-9.2)$ & $-6.2(-6.9,-5.7)$ & $-9.1(-9.6,-8.6)$ & $-6.1(-6.7,-5.5)$ \\
\hline 2 years & $-8.0(-8.6,-7.3)$ & $-4.6(-5.3,-3.9)$ & $-7.8(-8.5,-7.2)$ & $-4.9(-5.6,-4.2)$ \\
\hline 3 years & $-6.4(-7.3,-5.6)$ & $-3.5(-4.2,-2.8)$ & $-1.5(-2.0,-1.0)$ & $-0.3(-0.9,0.2)$ \\
\hline
\end{tabular}

Table 3 Estimated weight changes [mean $(95 \% \mathrm{CI})$ ] based on repeated measures modelling of the raw data and intention-to-treat, assuming return to baseline weight in people no longer attending. 


\begin{tabular}{|l|c|c|}
\hline & All & At least 2 visits \\
\hline Max. \% weight loss & $7.6(7.1,8.1) \dagger$ & $9.2(8.6,9.7) \ddagger$ \\
\hline Factors contributing to maximum \% weight loss \\
\hline Age & $0.07(0.02,0.12) \dagger$ & $0.06(0.01,0.11)^{*}$ \\
\hline Body mass index & $0.08(0.01,0.14)^{*}$ & $0.09(0.02,0.16)^{*}$ \\
\hline Systolic blood pressure & $0.03(0,0.07)^{*}$ & $0.03(-0.01,0.06)$ \\
\hline Smoker & $-1.47(-2.94,0.01)$ & $-1.48(-3.14,0.17)$ \\
\hline Mental illness & $-1.05(-2.23,0.13)$ & $-1.12(-2.42,0.18)$ \\
\hline
\end{tabular}

Table 4 Mean maximum \% weight loss recorded during the three years for all 1109 patients, and for those $(n=922)$ who attended at least one appointment after their initial visit [mean (95\% CI)]. Also included are the factors identified in the logistic regression model as contributing to maximum $\%$ weight loss. $* \mathrm{p} \leq 0.05, \dagger \mathrm{p} \leq$ $0.01,+\mathrm{p}<0.001$ 


\section{FIGURES}

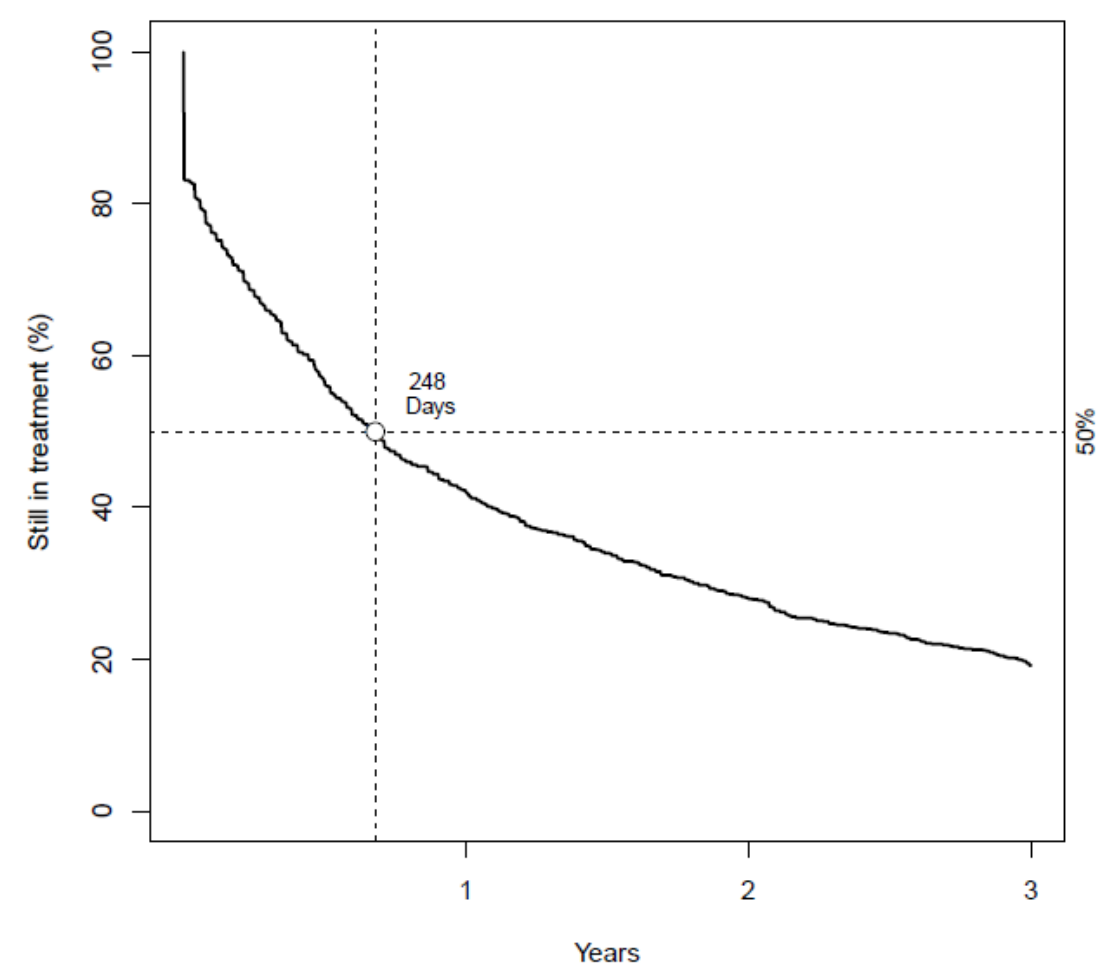

Figure 1. Percentage of patients still in treatment over time.
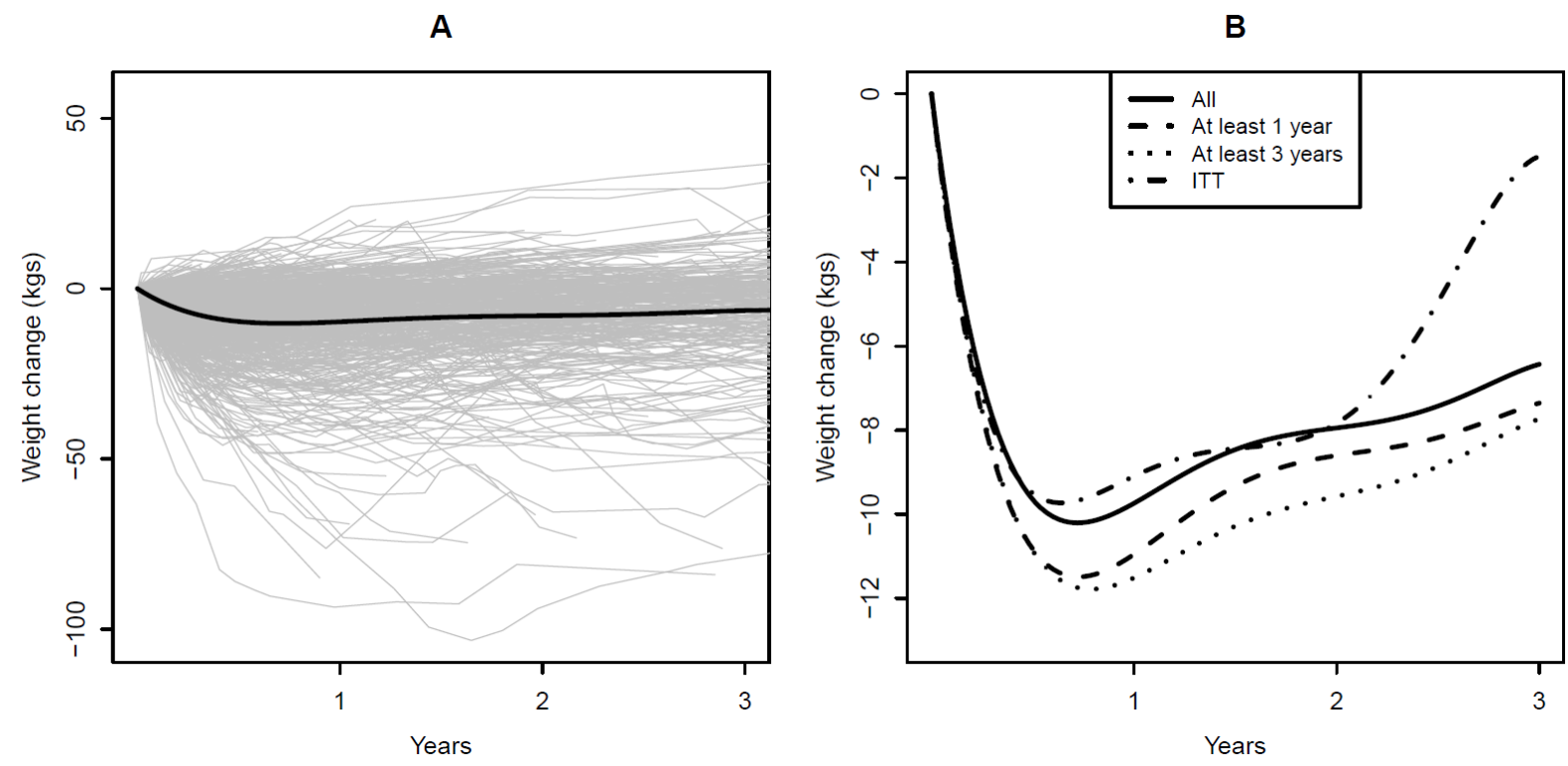

Figure 2. A. Individual weight change $(\mathrm{kg})$ over time $(\mathrm{n}=1109)$. B. Weight change modelled over time for all patients who started the VLED (solid line), those who attended at least once one year (dashed line) and three years (dotted line) after their initial visit, and intention-to-treat (ITT) analysis (dot-dash line) assuming return to baseline weight in people no longer attending the clinic. 


\section{TABLE AND FIGURE LEGENDS}

Table 1. Baseline characteristics. For descriptives, $n=1109$. For comorbidities, $n=1029$ 1032. * includes depression, anxiety, bipolar disorder, schizophrenia.

Table 2 Estimated odds-ratios [OR $(95 \% \mathrm{CI})]$ for factors contributing to probability of still attending the clinic at 1 and 3 years after the initial appointment. $* p \leq 0.05, \dagger p \leq 0.01,+$ $\mathrm{p}<0.001$. Prediction rate $(\%)$ refers to the strength of the model with respect to predicting whether or not a patient is still attending at the nominated time-point.

Table 3 Estimated weight changes [mean $(95 \% \mathrm{CI})$ ] based on repeated measures modelling of the raw data and intention-to-treat, assuming return to baseline weight in people no longer attending.

Table 4 Mean maximum \% weight loss recorded during the three years for all 1109 patients, and for those $(n=922)$ who attended at least one appointment after their initial visit [mean $(95 \% \mathrm{CI})]$. Also included are the factors identified in the logistic regression model as contributing to maximum $\%$ weight loss. $* \mathrm{p} \leq 0.05, \dagger \mathrm{p} \leq 0.01, \ddagger \mathrm{p}<0.001$

Figure 1. Percentage of patients still in treatment over time.

Figure 2. A. Individual weight change $(\mathrm{kg})$ over time $(\mathrm{n}=1109)$. B. Weight change modelled over time for all patients who started the VLED (solid line), those who attended at least once one year (dashed line) and three years (dotted line) after their initial visit, and intention-totreat (ITT) analysis (dot-dash line) assuming return to baseline weight in people no longer attending the clinic. 


\section{University Library}

\section{- M M N E R VA A gateway to Melbourne's research publications}

Minerva Access is the Institutional Repository of The University of Melbourne

Author/s:

Sumithran, P;Prendergast, LA;Haywood, CJ;Houlihan, CA;Proietto, J

Title:

Review of 3-year outcomes of a very-low-energy diet-based outpatient obesity treatment programme

Date:

2016-04-01

Citation:

Sumithran, P., Prendergast, L. A., Haywood, C. J., Houlihan, C. A. \& Proietto, J. (2016). Review of 3-year outcomes of a very-low-energy diet-based outpatient obesity treatment programme. CLINICAL OBESITY, 6 (2), pp.101-107. https://doi.org/10.1111/cob.12135.

Persistent Link:

http://hdl.handle.net/11343/123868 